\title{
DIGITAL SURVEYS AND 3D RECONSTRUCTIONS FOR AUGMENTED ACCESSIBILITY OF ARCHAEOLOGICAL HERITAGE
}

\author{
Massimiliano Campi, Antonella di Luggo, Daniela Palomba, Rosaria Palomba \\ Department of Architecture University of Naples Federico II, Via Forno Vecchio n.36, Napoli, Italy, (massimiliano.campi, \\ antonella.diluggo, daniela.palomba, rosaria.palomba@unina.it)
}

\section{Commission II}

KEY WORDS: 3D reconstructions, theatre of Benevento, cultural heritage, augmented reality, digital surveys

\begin{abstract}
This paper presents part of the results of a larger research project that focused on the surveying and documenting of Roman theatres and amphitheatres in the Campania region as well as the testing of a virtual fruition system for the digital reconstruction of a case study: the Roman theatre of Benevento. The work was carried out by the research group at the Interdepartmental Urban/Eco Research Centre of the University of Naples Federico II in collaboration with Spinvector, a company specialized in ICT - Information and Communication Technology - which lead to the defining of a fruition system of Cultural Heritage applied to archaeological heritage.

The project included 3D digital surveys of the study samples carried out using reality-based techniques, which allowed for the acquisition of metric, morphological, geometric and colorimetric data. This made it possible to elaborate three-dimensional models, based on the current configuration of the places as well as of the possible original reconfigurations.
\end{abstract}

\section{INTRODUCTION}

The possibility to use the new communication systems to explore and understand both tangible and intangible architectural heritage, not only allows to amplify the way of communicating information, but also to identify tools that are attractive and engaging for a growing audience.

The project presented starts from the premise to describe through research and studies the Roman theatres and amphitheatres in the Campania region, with it having different operational phases. They regard the activities and surveys of the heritage, the acquisition and processing of dimensional and formal data as well as the designing of a device for the fruition of cultural assets, used in this context, for a particular archaeological site.

The often intrinsic nature of archaeological sites lies in the lack of integrity of the heritage itself, which manifests itself through the image of a place that only partially manages to evoke its original configuration. Therefore, the desire to fill the possible gaps present along with making these places legible, usable and interpretable, drives and stimulates to identifying and testing fruition projects that use digital technologies and devices based on the use of both Virtual Reality as well as Augmented Reality. As part of the research project, an interactive display device was created in augmented reality for a specific test site, the Roman theatre of Benevento (Figure 1).
To this end, after the surveying and 3D modelling phases, an augmented reality display system was designed and implemented for the digital fruition of the archaeological heritage in a possible original configuration scenario.

\section{RELATED WORKS}

The contemporary cultural panorama sees in visual communication, in the communication that identifies in the language for images, an effective and increasingly widespread model through which to convey knowledge, information as well as describe more or less complex concepts.

It is in this panorama that the number of applications is multiplying and multimedia modalities are being tested, rather than multi-sensory ones, to divulge cultural contents, describe places and enjoy remote visits to virtual sites, rather than access enjoyable content during the actual on-site visit. Immersive and interactive photographs and interfaces, videos, three-dimensional reconstructions are just some of the possible variations of the new languages. "Three-dimensionality and virtuality are the key characteristics of the new trend. These distinctive elements, reaffirming the importance of the images and emotions aroused by them, aim to recover the reticular structures that characterize our processes of knowledge” (Meschini 2011).

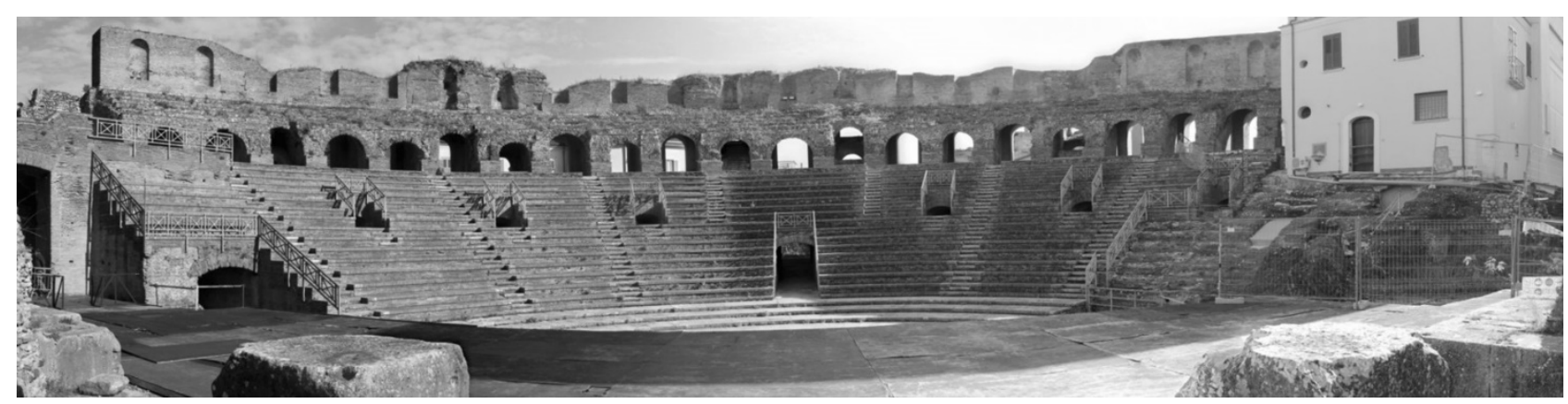

Figure 1: The Roman theatre of Benevento, the cavea. 

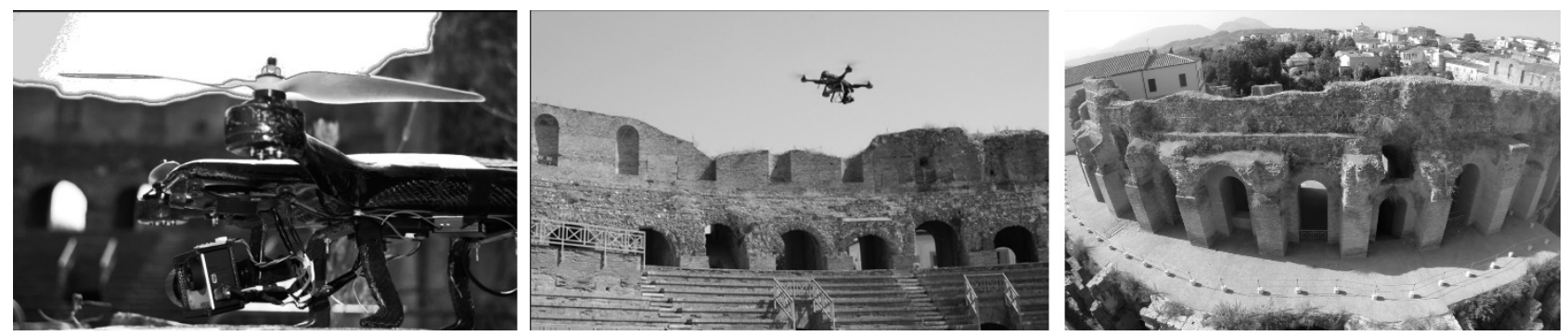

Figure 2: Theatre of Benevento, survey image-based with Unmanned aerial vehicle.

There is no doubt that the fascinations these tools produce, the possibility of activating evolved educational processes, lead to the need to innovate and renew interactions with cultural heritage in general. It is therefore necessary to reconsider the role and language that the scientific community can adopt, along with the involvement of the different professionals who can be part of these contexts: from art historians to archaeologists, from experts in digital survey techniques and 3D modelling to computer programmers, without neglecting the role of museum institutions and cultural places in general.

\section{DEVELOPED METHODOLOGY}

The methodology used saw the identification and distinction of different operational phases that characterized the activities aimed at the realization of the fruition and communication project of the archaeological heritage. As previously mentioned, the research activities dedicated to the test site were preceded by multiple studies and surveys carried out on the archaeological sites in Campania, theatres and amphitheatres, which were identified as examples of a cognitive process that uses the survey as an instrument of knowledge for the documentation and validation and/or exploration of new configurative theories of ancient architectures (Campi 2017). It is possible to identify four phases that highlight the methodological line followed which, at least for the former, follows established and stable processes (Remondino 2011). The first phase related to the analysis of the sources, linked to the necessary and detailed knowledge of the historical, architectural and documentary aspects, with studies that made it possible to reconstruct the history and transformations of the heritage. The second regarded the direct knowledge of the heritage through the acquisition of metric and architectural data. The survey campaign was carried out using reality-based technologies, with the combined and integrated use of range-based and image-based techniques. The third phase regarded the realization of a model of the state of the places as well as a three-dimensional model of the reconstructive hypothesis of the original configuration. The fourth phase was dedicated to the designing and implementing of the display device in Augmented Reality, the DIVAR (Figure 2).

\subsection{Case study}

The Roman theatre of Benevento was chosen as a case study upon which to carry out tests. The choice was made on the basis of pertinent aspects relating to its historical and archaeological characteristics as well as in consideration of the possibility to use advanced technologies for both the surveying operations as well as the visualization modalities of a context that only partially recalls the original characteristics.

The current image of the ancient theatre, hidden for centuries and engulfed by the built-up area, is due to the demolition and restoration interventions of the various accretions started in the early 1920s by Roberto Pane and only completed in 1950. The restoration interventions also included the reconstruction of some parts, which caused quite a few criticisms due to them being reputed by some historians questionable under the scientific profile and philological restoration (Figure 3 ).

Its dating has also been under discussion, with dating it back to the time of Emperor Trajan and others between 126 and 128 B.C.. Going along a long avenue that runs besides the basilicas and the back of the scena, it is possible to access the cavea. The auditorium, the place designated for the performance, can be reached by crossing one of the two basilicas, the one that still preserves traces of the polychrome marble decoration, and from here or through the aditus maximus, the side entrance, rather than the annular corridor, leads to the orchestra and cavea.

The cavea, oriented to the north-west, rests on a system of radial arches with several orders, in total twenty-five, unfortunately not all of them remaining. The cavea is divided into seven voussoirs, the radial sectors of the steps separated by ladders and vomitoria and, originally, articulated in ima, in media, of which there are only a few steps remaining and the summa cavea which collapsed.

Only the first level with large niches and three partially preserved entrances remain of what was an impressive scaenae frons. The

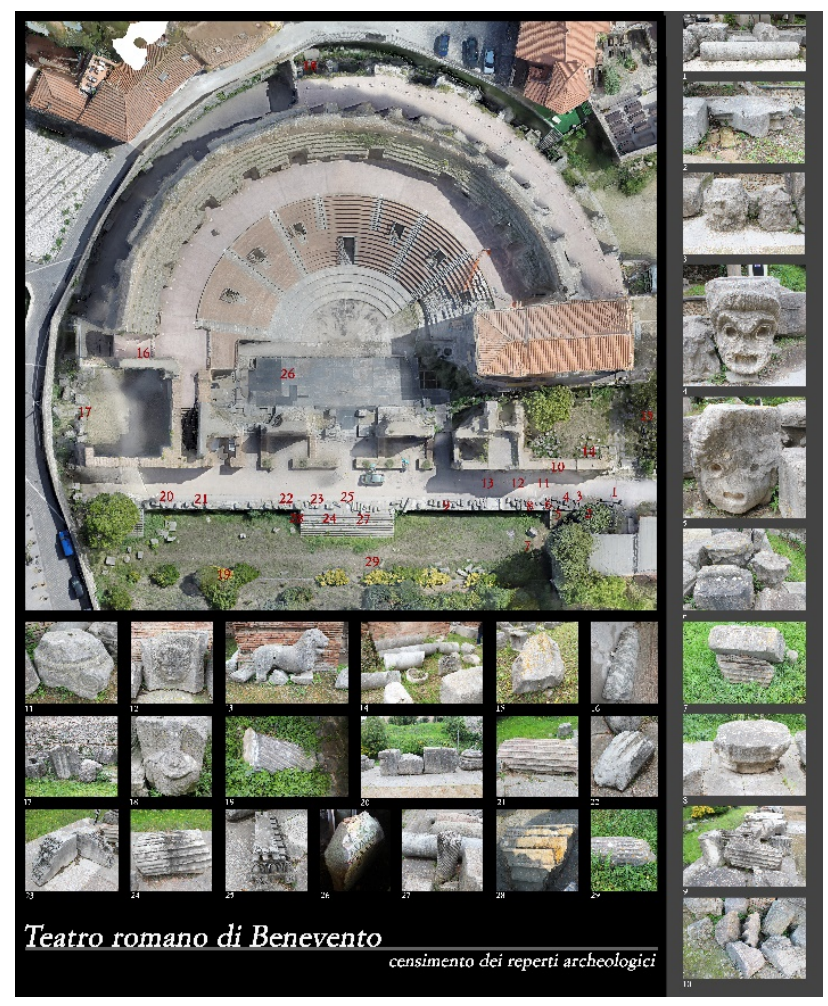

Figure 3: Census and survey of archaeological finds. 

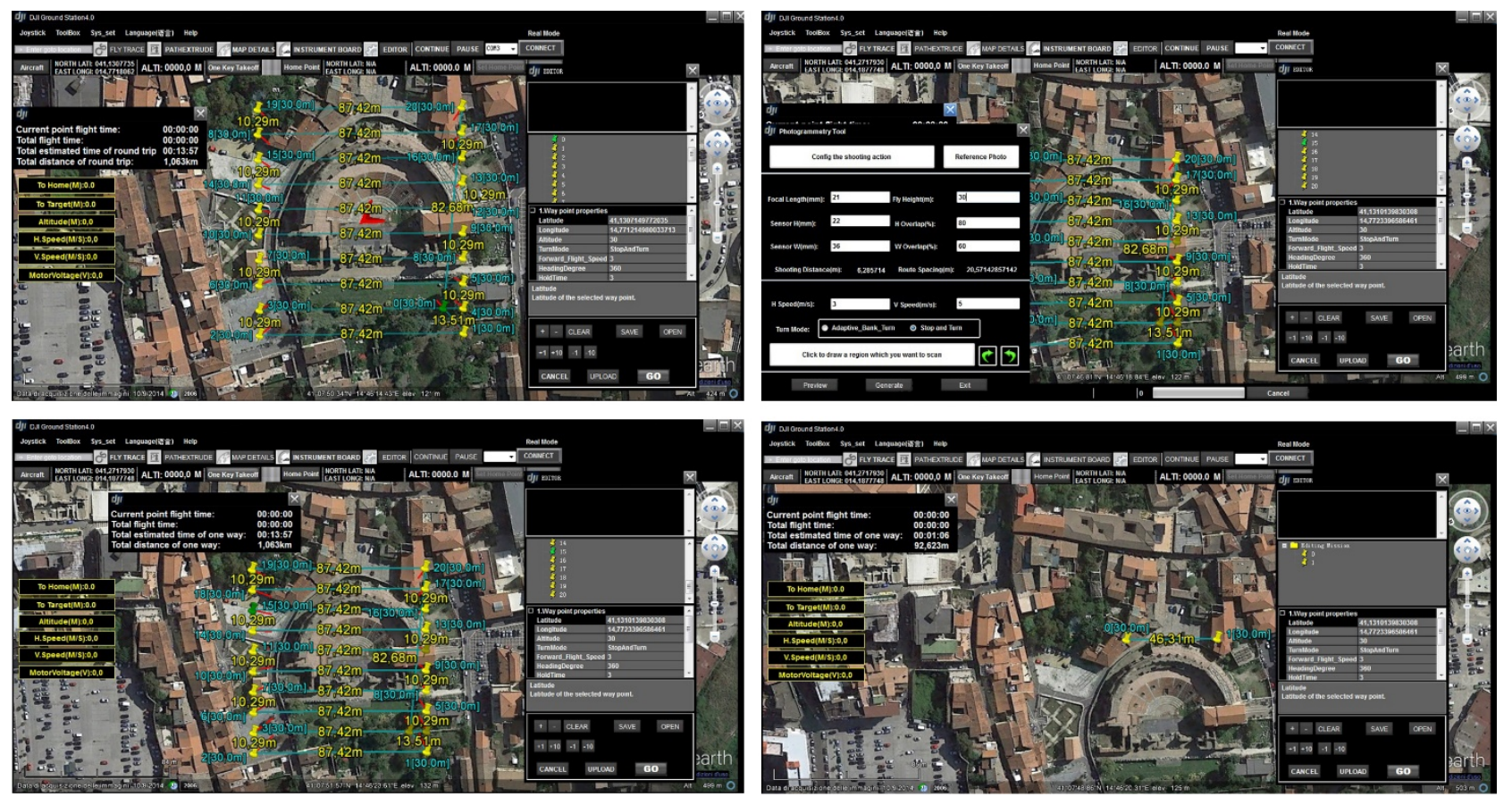

Figure 4: Setting the Flight Plan Using DJI Ground Station 4.0 Software.

original structure had an imposing Corinthian colonnade on three superimposed orders, of which there are still numerous on site findings that rae testimony of the precious marble used: pavonazzetto, ancient yellow and African.

\subsection{Digital surveys}

The choice of technologies and survey methods adopted was influenced by the architectural characteristics and accessibility of the place as well as its relationship with the context in which it is located. The use of non-invasive, no-contact 3D technologies for the acquisition of metric and colorimetric information becomes even more effective and indispensable when working in archaeological contexts, often characterized, as in this case, by inaccessible and/or small spaces unsuitable for carrying out surveys under safe conditions for both the operators and the instruments used. It was therefore necessary to carry out a digital survey by integrating range-based techniques, which included the use of active sensors such as a terrestrial laser scanner and total station, and image-based techniques, which used passive sensors based on photogrammetric algorithms (Figure 4, Figure $5)$.
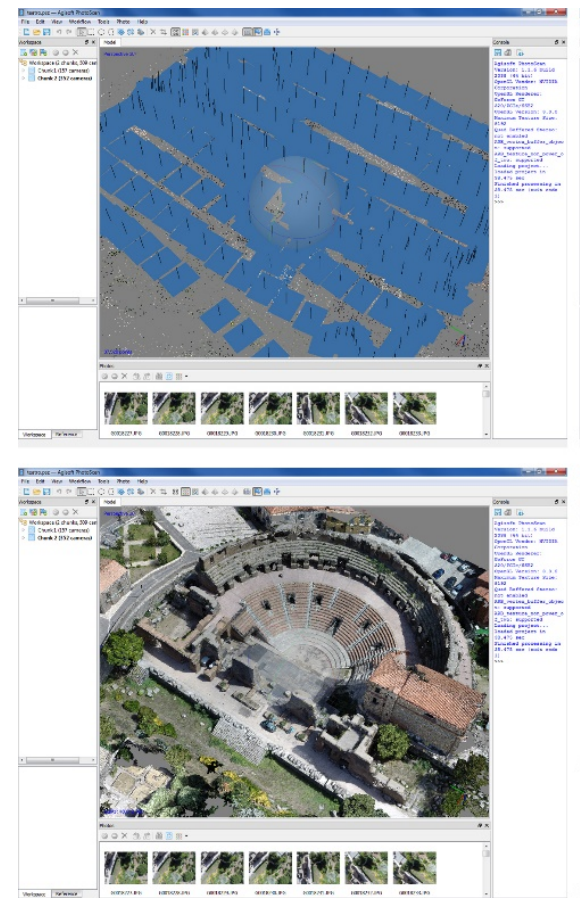
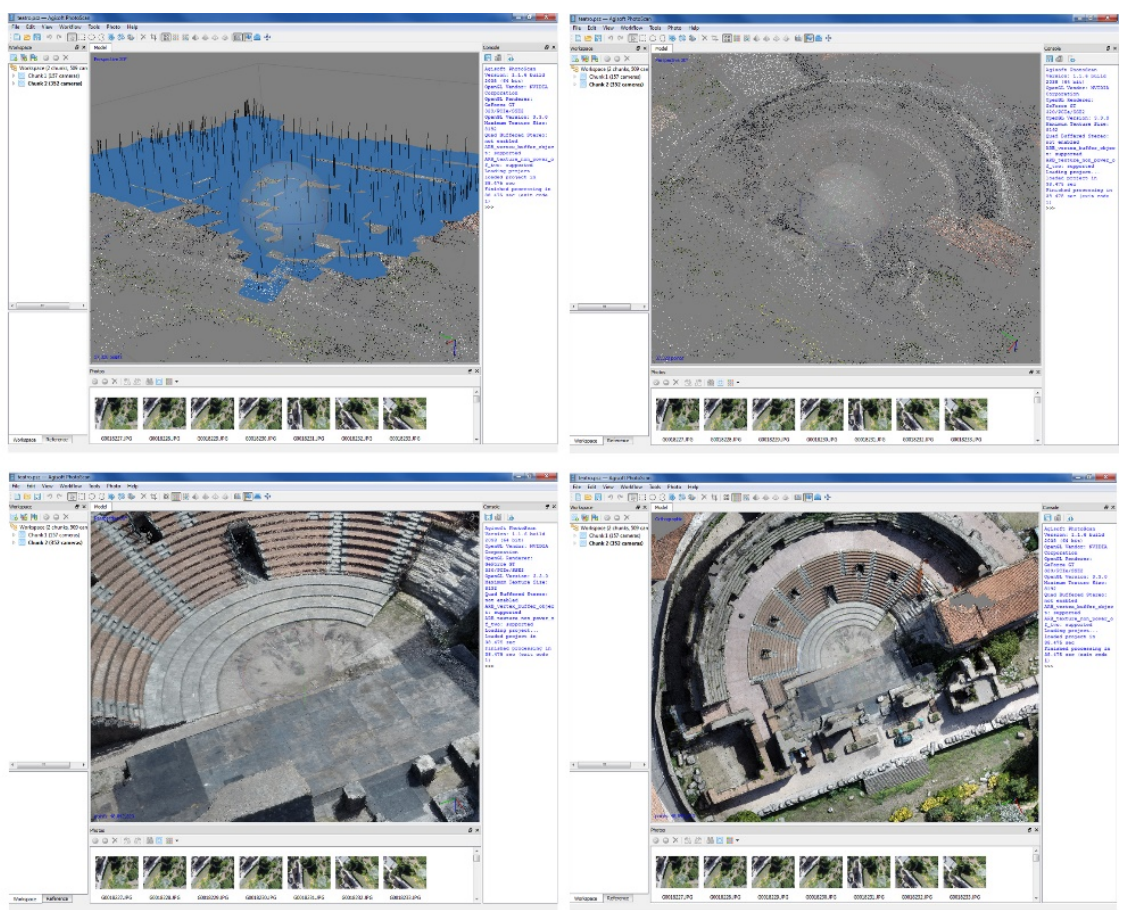

Figure 5: The post-processing phase was carried out using the Agisoft Photo-Scan software. 


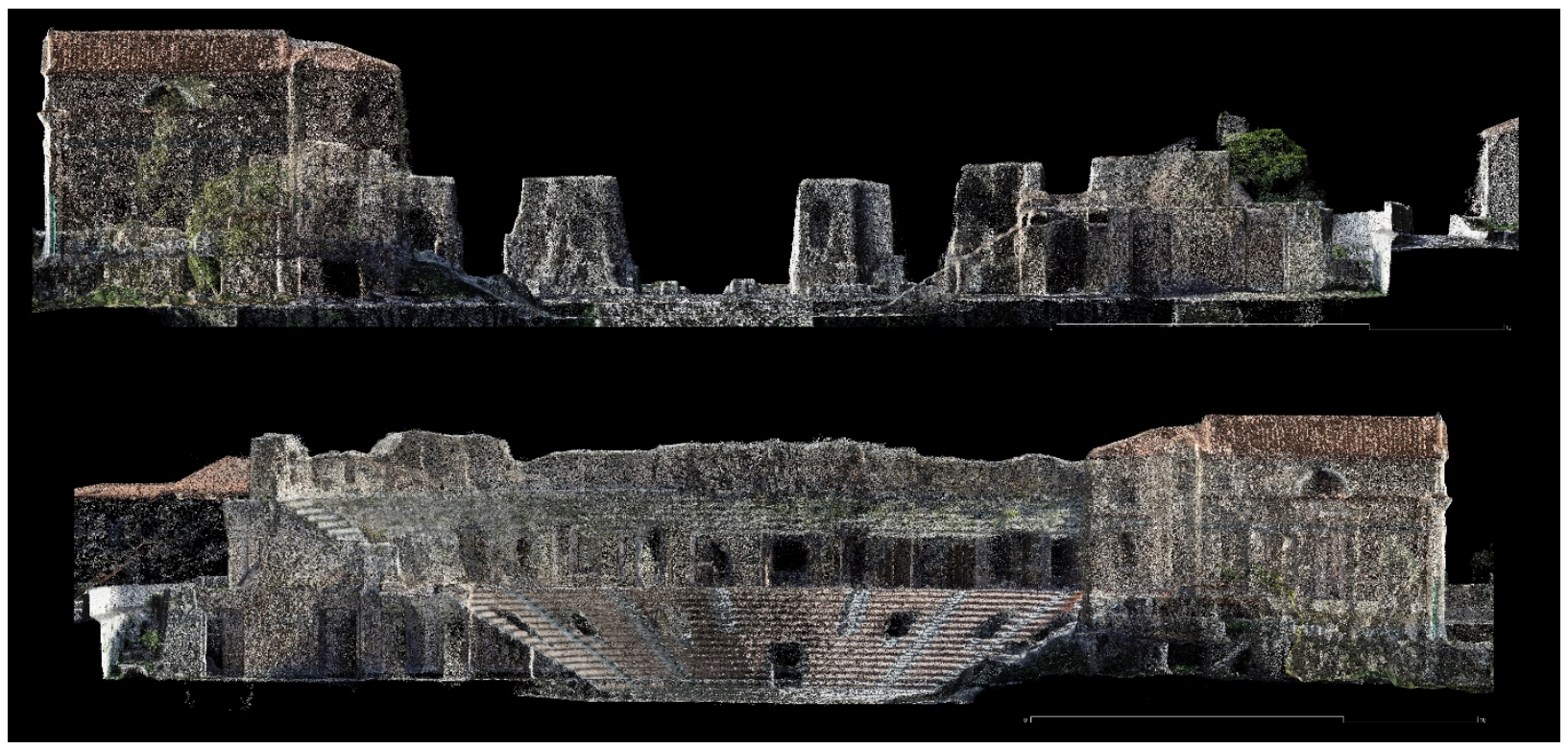

Figure 6: Orthophotos from the point cloud. Sections towards the scaenae frons and towards the cavea.

It is also necessary to highlight how digital surveys are particularly effective and convenient, not only due to the possibility to acquire accurate metric and morphometric data in a short time, but also the management of models characterized by particular complex geometries. A complexity that in this case not only refers to the formal components of the site, but also to the alterations and irregularities that these configurations have undergone due to the modifications, the collapses that have occurred over the centuries and the variable morphological characteristics.

The laser scanner survey was carried out with a CAM2 FARO Focus3D X 120 phase modulated scanner and was used to survey the internal spaces and architectural elements, such as ambulatories, corridors and vomitoria. The semi-circular system of the ambulatories, as well as the complex articulation of the corridors, along with the not always optimal lighting conditions of the rooms led to the use of the laser scanner that was able to return a three-dimensional model through 15 scans by setting a definition that guaranteed the surveying of a point every $6 \mathrm{~mm}$ at

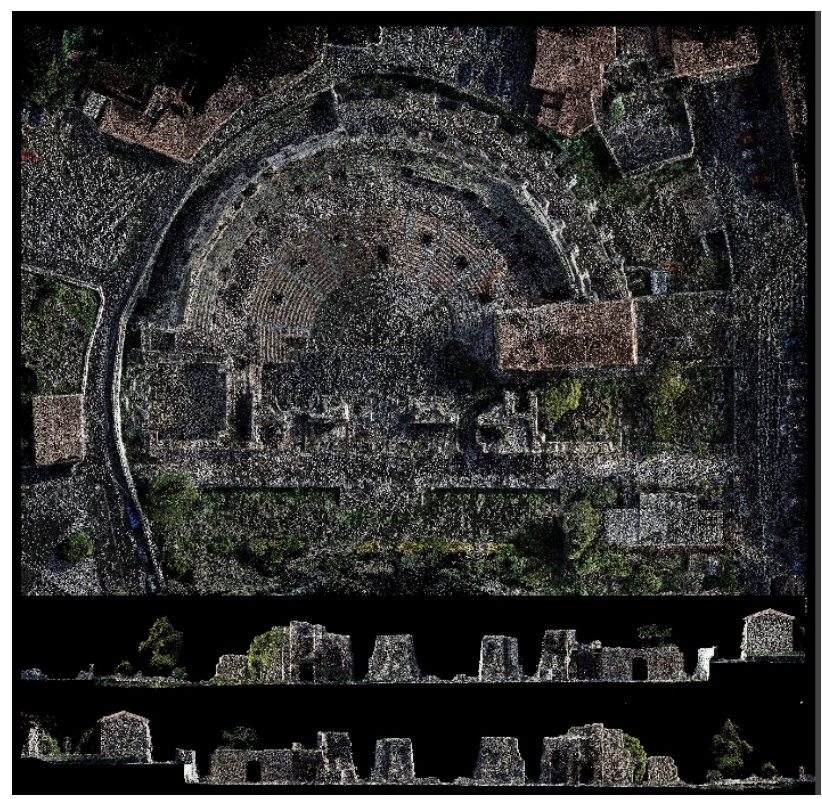

Figure 7: Orthophotos from the point cloud. a distance of 10 metres. In order to facilitate the subsequent processing and alignment phase of the individual scans acquired, 6 spherical targets and various chessboard targets were used, using semi-automatic procedures to recognise them. The resolution settings chosen resulted in a scan time of each scan of approximately six minutes. The data processing phase was carried out with the FARO Scene software. Integrated with a topographic survey, carried out using the Topcon GPT 3100 total station, it was possible to geo-reference the pointsclouds obtained from the laser scanner survey, thus allowing it to be verified and integrated with the photogrammetric survey (Figure 6, Figure 7).

These data were integrated with the surveys of the external spaces, which used a camera mounted on a Leonardo drone, an UAV - Unmanned aerial vehicle - with 4 propellers, a 2/2 twill balanced carbon-fibre frame 3k $500 \mathrm{~mm}$ wheelbase, with a DJI NAZA M V2 flight controller with GPS module, PMU V2. Two 2200 mAh parallel-mounted batteries were used, with a single flight lasting 20 minutes.

The surveys were based on the use of a planned flight that guaranteed coverage of the entire area of interest. A detailed and preventive planning of the shooting operations allowed to limit the gaps and minimize the noise. The surveyed area, covering about 1000 square metres, was acquired through 10 parallel strips, in a time of about 14 minutes and with $a$ total round-trip distance of $1.063 \mathrm{~km}$. The camera used, a GoPRO Hero 3+ optics, took 997 high-resolution nadiral images that, once processed, allowed for the processing of a dense cloud as well as a photorealistic 3D model.

The flight plan was elaborated using the DJI ground Station 4.0 software, setting the parameters for an altitude at 30 metres, a Forward_Flight_Speed of $3 \mathrm{~m} / \mathrm{s}$, a focal length of $21 \mathrm{~mm}$ - a Hold Time of 3 seconds, with crawl parallel, having an overlap of $80 \%$ and a sidelap of $60 \%$.

The data acquired with the planned flight were added to those necessary to ensure the recovery of the external porticoes for a total of 1258 images. Manual mode flights were also carried out due to the environmental conditions linked to the irregularity of the routes, with the camera being rotated both at $45^{\circ}$ as well as in the zenith position so as to ensure a more complete coverage in the recovery phase.

The subsequent post-processing phase was carried out using the low-cost Agisoft Photo-Scan software, based on the use of 


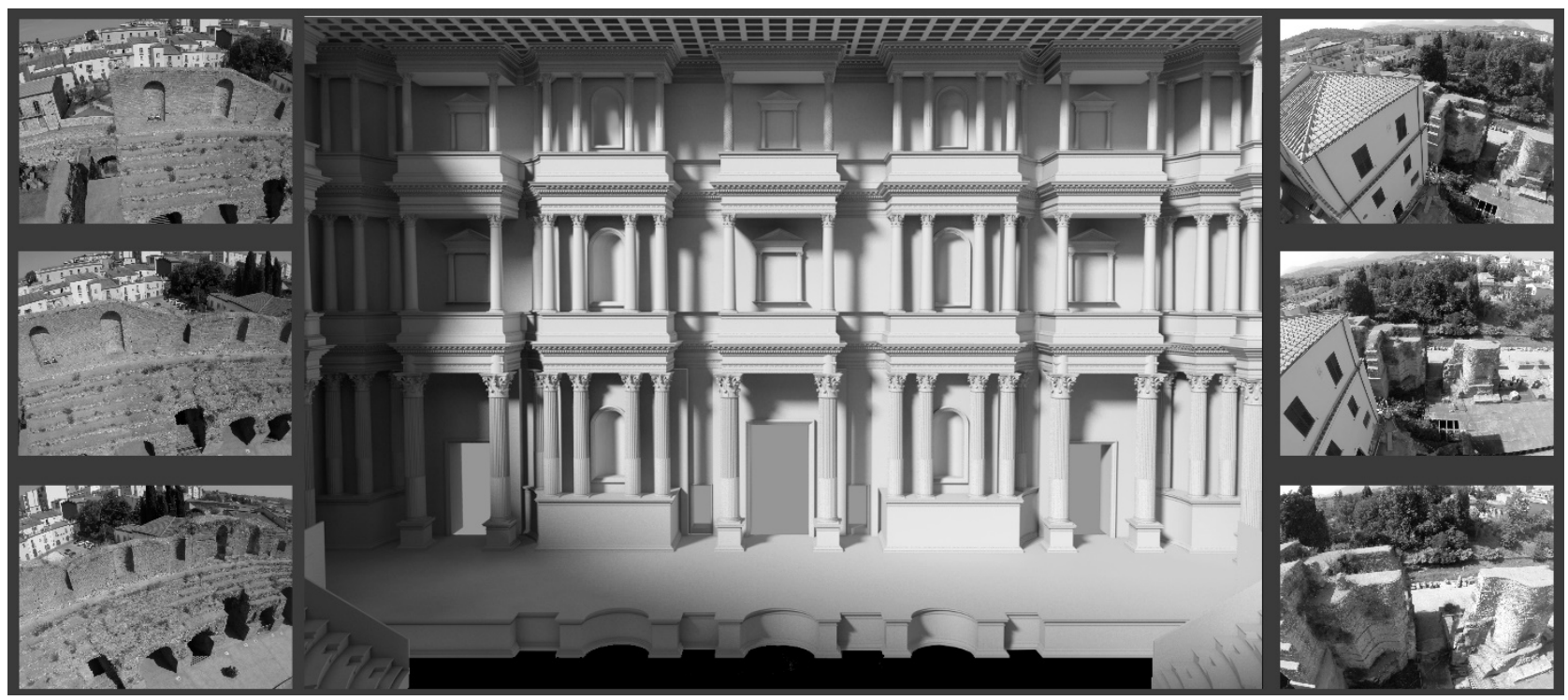

Figure 8: Reconstruction of the scaenae frons.

algorithms for automatic frame orientation. The dense clouds obtained from the aligned datasets, allowed to define the model of the cloud that was brought to scale thanks to the metric data acquired both through direct surveys as well as the range-based techniques used.

To obtain the dense point cloud, the shots were divided into two chunks of 157 oblique sockets and 352 nadiral shots respectively in the software. After the orientation and verification of any errors, it was possible to process the dense point cloud.

It is also important to note that a detailed and direct survey activity was carried out for the numerous findings placed and found in the archaeological area. Columns, capitals, cornices and entablatures were identified and the object of both a photographic survey and a direct survey. Accurate cognitive operations were carried out to identify their original destination and location. Studies that dealt with both the formal and dimensional characteristics were carried out with the aim of creating, in a figurative anastylosis project, the virtual reconfiguration of the places according to the hypotheses put forward by archaeologists.

\subsection{D Reconstruction}

The long and detailed cognitive survey was functional to the realization of a 3D model of the Roman theatre. Starting from the metric data obtained from the surveys, it was possible to realize a first modelling of the current state and then elaborate a 3D CAD model of the reconfiguration hypothesis of the theatre. The reconstructive hypothesis first proposed by Meomartini (Meomartini 1889) and then elaborated by Professor Pensabene (Pensabene 2005) were examined and verified by detecting the places and elements found on site, such as capitals, entablatures and cornices. The direct and indirect surveys made it also possible to realize a complete three-dimensional model of the detailed components obtained from the surveys of the archaeological findings (Figure 8).

The 3D CAD models were the subject of a demanding and detailed processing to be used in the augmented reality management program.

The need to manage an optimized model (Figure 9) made it necessary to identify those repeatable and identifiable elements as instances.
These elements were modelled starting from CAD files, optimizing them as a number of polygons, in order to allow their real-time use. Once the model was created, it was necessary to identify the most effective and coherent textures with the materials detected and/or hypothesized, combining manual and procedural elaborations.

This process was significantly shared between the parties and implemented thanks to the continuous synergy and interaction between the research group responsible for the scientific, archaeological, and architectural aspects with the technological ones of the programmers and 3D modellers. The reconfiguration of the site started from the graphic elaboration of the scaenae frons that was articulated on three orders for a total height of about 23 metres and a width of 43 metres (Pensabene 2005). At the centre, there was the Porta Regia that had two majestic pavonazzetto marble columns with a diameter of $90 \mathrm{~cm}$ and two smaller symmetrically arranged openings to the sides. The scenic apparatus also had two other passages at the ends, the hospitalia, with columns on pedestals to the sides that were similar to the central ones but in antique yellow marble. On the sides of the Porta Regia, there were to two podiums with a curvilinear side, upon which five columns stood that framed the apsed niches. Two other podiums delimited the scene. There were 16 cabled columns in antique yellow marble with a diameter of $72 \mathrm{~cm}$, placed on podiums, for a total of 22

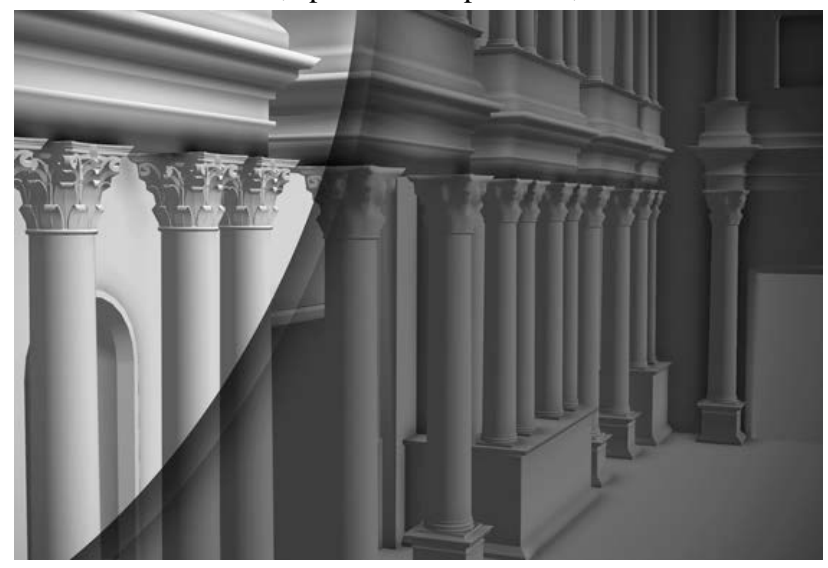

Figure 9: 3D model optimized for use in AR. 

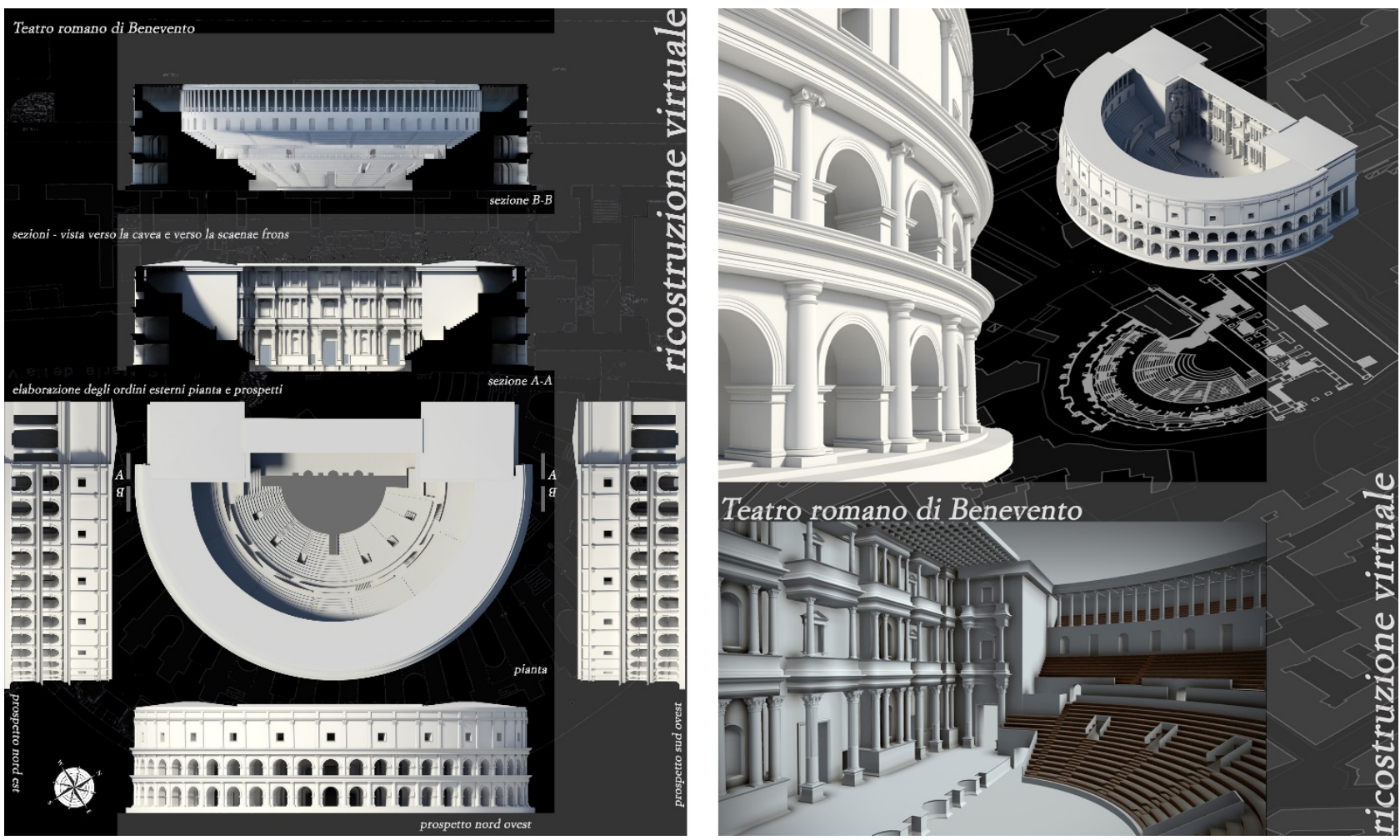

Figure 10: 3d model of the reconstructive hypothesis of the theatre of Benevento.

columns for the first order of Corinthian capitals. The composition of the two higher orders was similar, with the exception of the materials used and the size of the elements. The second order had columns with a diameter of $60 \mathrm{~cm}$, placed on pedestals and the smooth stem in African marble. The composition of the third order was similar, which, like the other two, had Corinthian capitals. These, like the columns, were smaller. The columns of the last level were probably made of antique yellow marble, with slotted and cabled stems with a diameter of $44 \mathrm{~cm}$. The continuity of the order was interrupted by the two Solomonic columns in pavonazzetto marble, which, as for the first order, marked the centrality of the composition. The tripartite articulation of the scaena was reproposed for the two parascaenia that delimited the stage. The latter, covered in wood, presented towards the orchestra a wall marked by three

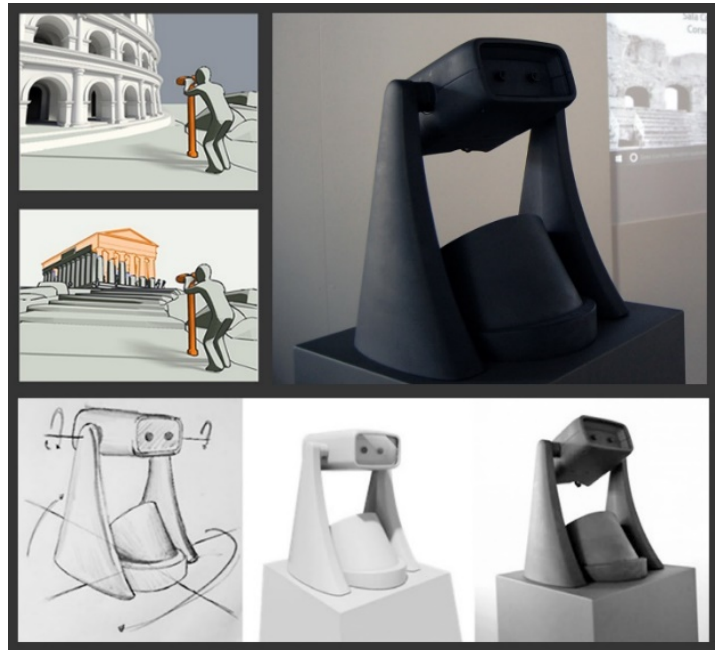

Figure 11: DIVAR. Below sketch, 3D Model and Device Made (photo and SpinVector processing) curvilinear front niches interspersed with others with a rectangular profile.

The sizing of the scenic apparatus allowed to define and hypothesize the articulation of the cavea that ended with a porticus that was the same height as the scenic building. It must have been a majestic piece of architecture. The diameter of the cavea reached a width of 93 metres, while the orchestra occupied a semicircular sector with a diameter of 25 metres. Access to the steps of the ima cavea was along eight steps, six of which arranged in axis with the vomitoria, which divided the cavea into seven voussoirs. The two staircases placed at the end of the cavea, gave access to the gallery upon which high walls concealed the system of ramps which lead to the media cavea. 49 granite columns punctuated the porticus of the summa cavea that stood on the high wall, still visible today, characterized by arched niches. Regarding the configuration of the external components, from the survey of the state of the site and the archaeological studies carried out, it emerges that the theatre had three majestic orders, of which only the first one is preserved. Both the first and second orders had twenty-five arches. The survey also showed how, contrary to what is indicated in the sources, the arches all had a width of 3.52 metres, with the exception of the central one which reached a width of $3.90 \mathrm{~m}$ and which allowed direct access to the orchestra and the two extremes with a light of $3.76 \mathrm{~m}$. Robust semi-columns with Tuscan capitals alternate with the arches of the first order, substituted by smaller Ionic style ones in the second level. The third one ended with a high wall, about 9.56 metres, and was punctuated by Corinthian pilasters surmounted by a slightly protruding cornice. In alternate sectors, the pilasters framed square windows that guaranteed the illumination of the summa cavea corridor (Figure 10).

\subsection{The DIVAR}

The evolved fruition model used in the project included the designing and construction of an AR device, which allows for the simultaneous display of virtual contents, processed in computer 

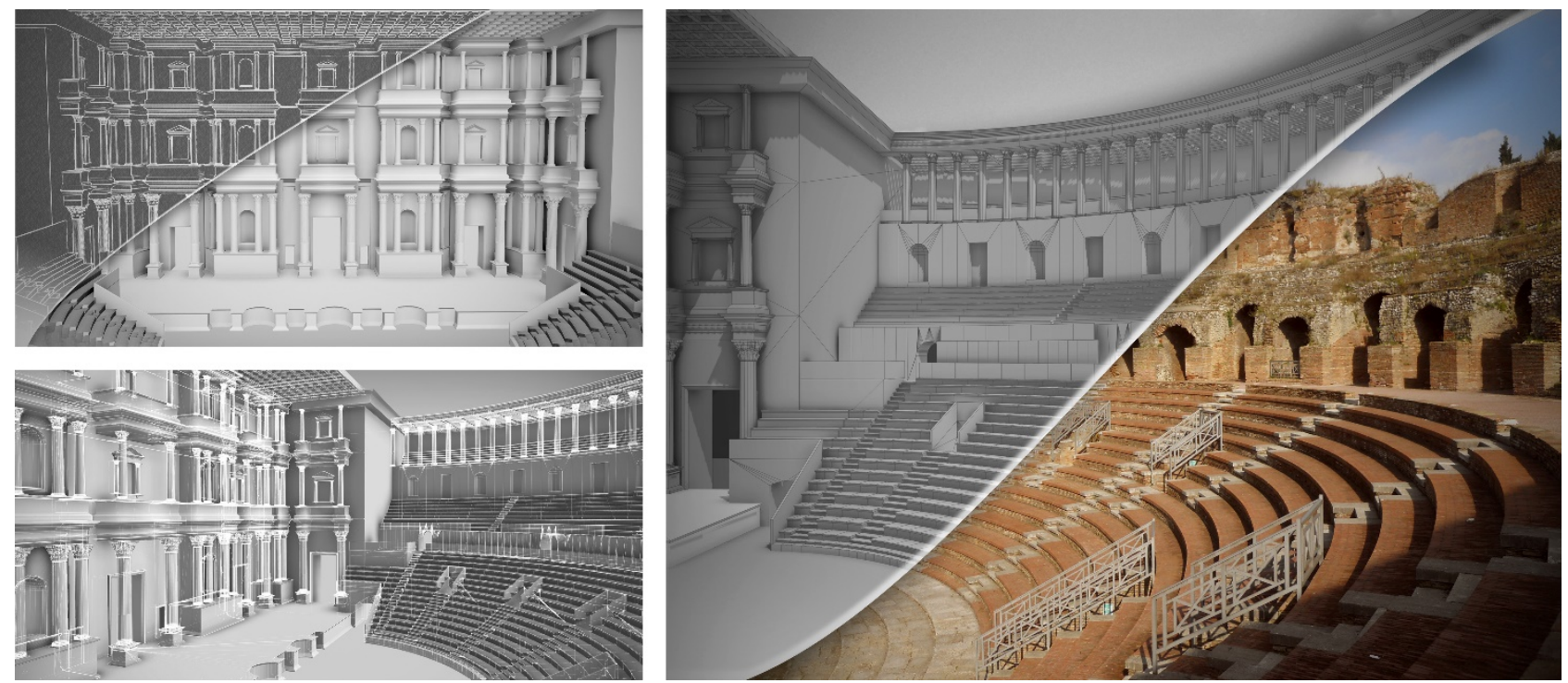

Figure 12: Discretization of the 3d model e matching between material and virtual reality.

graphics, read and displayed in direct relation with the physical realities for which it was designed. DIVAR, an acronym for Device for Interactive Visualization AR (Figure 11), was developed by Spinvector, a company specialized in Information and Communication Technology and a research project partner.

It is an enhanced pair of binoculars, designed and built to be installed on a fixed base at the archaeological site of the Roman theatre of Benevento and which allows to superimpose textual and graphical information contents to the observed reality. The device allows to use a virtual reconstruction, fully consistent with the current state from the dimensional and spatial points of view, offering the possibility of interactively visualizing the virtual space in its reconstructive hypothesis. DIVAR provides for the involvement and interaction with the user. Framing the scene, there are virtual buttons, or small icons that, displayed at the centre of the observed image, trigger the appearance of additional content, rather than captions, or allow for movement in the environment and the possibility to enjoy other possible views of the archaeological site.

As noted by Caturano (Caturano 2017), the effectiveness of the most advanced immersive AR systems consists in the successful integration and three-dimensional consistency between Material/Real and Virtual, in the possibility that the interaction takes place in real time and that stereoscopy is used for three-dimensional viewing, able to generate engaging and evocative immersive experiences. Stereoscopy, used in these contexts, allows for the creation of virtual scenes in which the depth of the scenes is appreciated more effectively, contributing to a greater realism of the scenes.

The characteristics of the display device and the software for the processing of rendering in real-time are of fundamental importance for the design of the DIVAR. For the first, an Oculus Rift visor was used, characterized by a large $100^{\circ}$ diagonal field-of-view and a high resolution for displaying convincing images. For the software design, the effectiveness is estimated based on the image processing time according to movement and based on the construction of possible scenes. The goal was achieved thanks to an optimization boost of the 3D model components as well as through the creation of customized shaders, for the control of the material effects and details and their behaviour in relation to the lights and shadows of the scenes. The DIVAR chassis components were made using 3D printing. There are two main parts, the binoculars and the base with a housing for weights used as ballast.

The binoculars have a horizontal rotation angle of $120^{\circ}$ and a vertical one of $90^{\circ}$ (Figure 12, Figure 13).

\section{CONCLUSIONS}

The presented project has been elaborated thanks to both the detailed planned actions as well as the competences lent and put in place by the different actors and partners. The need to involve multidisciplinary and specific technological skills was evident clear from the design phases of the project. While on the one hand, the digital technologies used are based on tested and consolidated methodologies, their integration and the possibility of optimizing their use is always the result of specific considerations identified for the individual contexts.

The need to produce a digital model of the archaeological site that was perfectly compatible and virtually integrated with the real site, made it necessary to not omit any details during the relevant activities. No correction of the computergraphic models was required for the matching operations between the real and virtual theatres.

The possibility and suggestions offered by other viewing modes suggest testing increasingly effective visual codes and visual languages.

The visual design made of signs, spaces and images plays a central and essential role in the realization of the communication and understanding of contents. It is probably from these that the success, or the failure, of the access and participation of the users, visitors, citizens, to the cultural experiences proposed through virtual and digital experiences can derive and depend. (Ippoliti, Casati 2017).

\section{ACKNOWLEDGEMENTS}

The authors would like to thank all those who participated in this project and have collaborated both in the data acquisition, processing and modelling phases. The research was carried out as part of the research and development project entitled Le forme dell'Anfi/Teatro modello di fruizione evoluta: digitalizzazione, analisi e visualizzazione dei teatri romani in Campania, a project carried out as part of the POR Campania ERDF 2007-13, under the scientific coordination of Massimiliano Campi. A special thanks goes to Ing. Giovanni Caturano of Spinvector and his team of programmers, who are responsible for the designing and implementation of DIVAR. Thanks to dott. Francesco Pio Ferreri for the support and advice on the reading and interpretation of archaeological findings. 


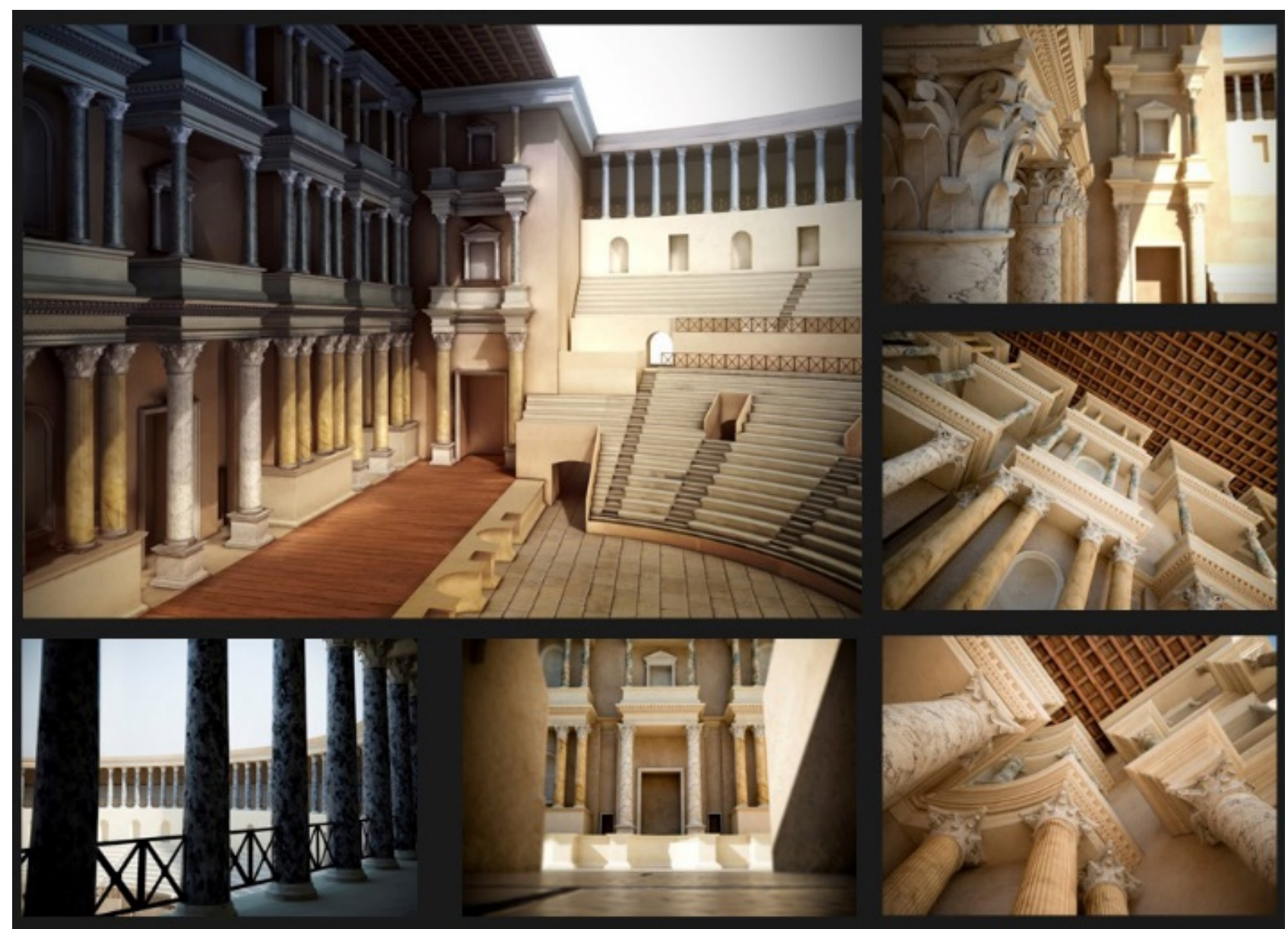

Figure 13: Views of the reconstruction carried out in AR. The advanced shaders allow to obtain very realistic light effects. The procedural variance parameters make each element different from the other similar instances, avoiding the need to model new elements.

\section{REFERENCES}

Campi M., 2017. Sistemi di conoscenza per l'Archeologia. I luoghi dei teatri e degli anfiteatri romani in Campania, Artstudiopaparo, Collana Grandi Opere, Napoli 2015 (Ristampa 2017), ISSN 2421 034X, ISBN 9788899130374.

Campi M., di Luggo A., Scandurra S., 2017. 3D modeling for the knowledge of architectural heritage and virtual reconstruction of its historical memory, in The International Archives of the Photogrammetry, Remote Sensing and Spatial Information Sciences, Volume XLII-2/W3, pp.133-139.

Caturano G., 2017. Il teatro Romano di Benevento, modello di fruizione evoluta: Realtà aumentata e Interazione, in Campi M., Sistemi di conoscenza per l'Archeologia. I luoghi dei teatri e degli anfiteatri romani in Campania, Artstudiopaparo, Collana Grandi Opere, Napoli 2015 (Ristampa 2017), pp. 169-176, ISSN 2421 034X, ISBN 9788899130374.

Guidi G., Russo M., Angheleddu D., 2014. 3D survey and virtual reconstruction of archaeological sites. Digital Applications, in Archeology and Cultural Heritage. http://dx.doi.org/10.1016/j.daach.2014.01.001.

Ippoliti E., Casale A., 2017. Rappresentare, comunicare, narrare. Spazi e musei virtuali tra riflessioni e ricerche, in Ambienti digitali per l'educazione all'arte e al patrimonio, a cura di Luigini A., Panciroli C., Milano, Franco Angeli.
Jacquemin C., Caye V., De Luca L., Favre-Brun. A., 2014. Genius Loci: digital heritage augmentation for immersive performance, International Journal of Arts and Technology (IJART), Vol. 7, No. 2/3.

Meomartini A., 1889. Monumenti della città di Benevento, Tipografia di Luigi De Martini e Figlio, Benevento.

Meschini A., 2011. Tecnologie digitali e comunicazione dei beni culturali. Stato dell'arte e prospettive di sviluppo. Disegnarecon, Vol. 4, n. 8, Tecnologie per la comunicazione del patrimonio culturale, a cura di Ippoliti E. e Meschini A., pp. 1424, ISSN 1828-5961.

Pensabene P., 2005. Marmi e committenze negli edifici di spettacolo in Campania, Marmora 1.

Remondino F., 2011. Rilievo e modellazione $3 D$ di siti e architetture complesse. 3D surveying and modelling of complex architectural sites and heritage objects, in Disegnarecon, Vol. 4, n. 8, Tecnologie per la comunicazione del patrimonio culturale, a cura di Ippoliti E. e Meschini A., pp.90-98, ISSN 1828-5961.

Russo M., Remondino F., Guidi G., 2011. Principali tecniche e strumenti per il rilievo tridimensionale in ambito archeologico, in Archeologia e Calcolatori n. XXII, Edizioni All'Insegna del Giglio, pp. 169-198. 